\title{
О возможности регулирования фотоэлектрического отклика полупроводников специальным пространственным профилированием потока излучения
}

\author{
В.А. Холоднов ${ }^{1,2}$ \\ ${ }^{1}$ Институт радиотехники и электроники им. В.А. Котельникова РАН, \\ Москва, 125009, Моховая ул., д. 11, кор. 7, факс: +7 (495) 629 3678; \\ ${ }^{2} \mathrm{OАО}$ «НПО «Орион». Россия, 111123, Москва, ул. Косинская, д.9 факс: +7 499373 6862; \\ тел:+7(916) 189-1128, эл.nочта:vkholodnov@mail.ru
}

DOI 10.34077/RCSP2021-58

В работах $[1,2]$ теоретически показано, что неоднородность плотности скорости фотогенерации (СФ) носителей $g(x)$ вдоль напряженности темнового электрического поля $\vec{E}_{0}$ (ось $x$ ) может радикально влиять на фототок $I_{p h}$. К каким возможностям вообще может приводить неоднородность $g(x)$ проанализировано в данной работе. Рассмотрен полупроводник вне приближения квазинейтральности (ПКН) при межзонной фотогенерации носителей, рекомбинацией через одиночный примесный уровень и слабом излучении. Теоретически показано, что при определенных профилях $g(x)$ могут проявиться три неизвестных фотоэлектрических эффектов. Это самоусиление, самогашение и самоинверсия знака $g(x)$. Рассчитаны общие формы соответствующих профилей. Эффекты обусловлены локальным фотовозбужденным объемным зарядом плотностью $\rho_{p h}$. Показано, что формы профилей зависят от параметров полупроводника, $\vec{E}_{0}$ и температуры. Решение основано на уравнении $[1,3]$

$$
Q \cdot \partial^{4} n_{p h} / \partial x^{4}-D \cdot \partial^{2} n_{p h} / \partial x^{2}+\mu E_{0} \cdot \partial n_{p h} / \partial x+n_{p h} / \tau_{n}=g_{e f}(x)
$$

где $Q, D$ и $\mu$ зависят от $\rho_{p h}$, величина которого характеризуется неким безразмерным параметром $\xi$ (в ПКН $\xi=0) ; n_{p h}(x)$ - концентрация фотоэлектронов, $\tau_{n}$ - их время жизни в ПКН;

$$
g_{e f}(x)=g(x)+B_{e f}(\partial g / \partial x)-A_{e f}\left(\partial^{2} g / \partial x^{2}\right),
$$

$A_{e f}=\xi D_{p} \tau_{p}, B_{e f}=\xi \tau_{p} \mu_{p} E_{0}, \tau_{p}$ время жизни дырок в ПКН, $D_{p}$ и $\mu_{p}$ - их коэффициент диффузии и подвижность. Из (2) видно, что при $g(x) \neq c o n s t$, в отличие от ПКН, $g_{e f}(x) \neq g(x)$. Поэтому назовем $g_{e f}(x)$ эффективной плотностью СФ. Левая часть (1) ответственна за диффузионно-дрейфовый коэффициент фотоэлектрического преобразования (ДДКФЭП) $[1,3] \quad G_{0}=I_{p h} /\left(q g_{e f}^{t o t}\right) \quad$ полной эффективной СФ носителей в образце $g_{e f}^{t o t}$ в $I_{p h} ; q$ - абсолютная величина заряда электрона. Для выяснения возможной степени влияния неоднородности $g(x)$ на ДДКФЭП $G=I_{p h} /\left(q g^{t o t}\right)$ полной истинной СФ носителей в образце $g^{t o t}$ в соответствие с уравнением (1) и выражением (2) рассмотрим уравнение $g_{e f}(x)=(1+\zeta) \cdot g(x)$, где $\zeta$ - некоторый рациональный безразмерный параметр. Тем самым, $1+\zeta=G / G_{0} \equiv \eta$, где $G_{0}$ - ДДКФЭП в ПКН, либо при $g(x)=$ const. Искомое решение имеет вид $g(x)=\mathrm{C}_{1} \exp \left(a_{1} x\right)+\mathrm{C}_{2} \exp \left(a_{2} x\right)$. Параметр $\zeta$ не связан с ДДКФЭП $G_{0}$. Поэтому $\zeta$ определяет следующие возможные типы профилей $g(x)$.

1. Самоусиливающий: $\eta=>1$, если $\zeta>0$. Сопротивление образца $R$ уменьшается больше, чем дает ПКН.

2. Самоослабляющий: $0<\eta<1$, если $-1<\zeta<0$. Уменьшение $R$ меньше, чем дает ПКН. 3. Самогасящий: $g_{e f}(x)=0$, если $\zeta=-1$. Излучение, хотя и генерирует носители, но не изменяет $R$. 4. Самоинверсирующий: $\eta<0$, если $\zeta<-1$, причем $|\eta|$ может превышать 1 . Излучение, хотя и генерирует носители, но увеличивает $R$. 5. Псведонейтральный: $\eta=1$, если $\zeta=0$ (ПКН дает такой же результат). Итак, специальное пространственное профилирование потока излучения открывает возможность. регулирования фотоэлектрического отклика полупроводников (от больше, чем дает ПКН, уменьшения до увеличения сопротивления образцов).

\section{Литература}

[1] V.A. Kholodnov //J. of Communication Technology and Electronics. 2019. V.64, is.9. P.1038-1045.

[2] V.A. Kholodnov, M.S. Nikitin // Electrica. 2021. V. 21, is.1, P. 168-172.

[3] V. A. Kholodnov and M. S. Nikitin // In the book: Optoelectronics - materials and devices, Ed. S. L. Pyshkin and J. Ballato (InTech 2015. Ch. 12, P. 301-348, www.intechopen.com). 